\title{
Pelatihan Desain Penelitian Tindakan Kelas bagi Guru MGMP Bahasa Inggris SMA Kabupaten Barito Kuala
}

\author{
Yansyah $^{1)}$, Hafizhatu Nadia ${ }^{2)}$, Tenny Murtiningsih ${ }^{3)}$ \\ ${ }^{1,2,3)}$ Universitas Muhammadiyah Banjarmasin \\ yansyah.hamarung@gmail.com
}

\begin{abstract}
ABSTRAK: Penelitian tindakan kelas (PTK) merupakan salah satu cara meningkatkan kualitas pembelajaran sekaligus profesionalitas guru. Namun, banyak guru yang masih bingung mengenai bagaimana memulai, membuat, dan melaporkan hasil PTK mereka. Artikel ini membahas tentang pengabdian masyarakat (PKM) yang dilaksanakan oleh dosen prodi pendidikan Bahasa Inggris Universitas Banjarmasin dalam membantu para guru MGMP Bahasa Inggris. PKM berbentuk pelatihan yang dilaksanakan selama satu hari dan ditindaklanjuti melalui bimbingan hingga artikel penelitian berhasil diterbitkan. Materi yang diberikan terkait tahapan-tahapan PTK, analisis artikel PTK, dan akses jurnal bereputasi sebagai sumber referensi. Metode pelatihan berupa ceramah, diskusi kelompok, dan praktik. Berdasarkan hasil wawancara dengan peserta dan observasi selama pelatihan, mereka merasa bahwa kegiatan ini sangat bermanfaat dalam meningkatkan pengetahuan dan keterampilan dalam meneliti. Sebagian peserta, bahkan, telah memiliki konsep tentang apa yang akan mereka teliti.
\end{abstract}

Kata kunci : Pelatihan untuk Guru, Penelitian Tindakan Kelas, MGMP

ABSTRACT: Classroom action research is a way to enhance the learning outcomes as well as to develop teacher's professionalism. However, some teachers do not know how to start, to conduct, and to publish their research. This article discusses a community service held by English Department lecturers of University of Muhammadiyah Banjarmasin. It was in form of a one-day training and will be followed up with a consultation until their works successfully published. The topics of training were steps for conducting classroom action research, analysis sample of action research article, and access for reputable journals as references. Techniques used in the training was lecture, discussion, and practice. Based on the the result of interview with particpants and observation during the training, the participants expressed that this community service is fruitful and improves their knowledge and skills in doing a research. Some participants, even, had made the concept of what they were going to research.

Keywords: Training for Teachers, Classroom Action Research, Local Teachers Forum

\section{PENDAHULUAN}

Penelitian tindakan kelas (PTK) merupakan cara yang bisa digunakan guru dalam meningkatkan kualitas pembelajaran di kelas. Berdasarkan pasal 20 tentang Undang-Undang Guru dan Dosen, guru berkewajiban untuk merencanakan, melaksanakan, menilai, dan mengevaluasi pembelajaran yang bermutu. PTK bisa menjadi alat yang efektif bagi guru dalam melaksanakan kewajiban tersebut. Latief (2012) menyebutkan bahwa melalui PTK guru bisa mengevaluasi pembelajarannya dan melakukan perbaikan berdasarkan hasil evaluasi tersebut. Hasil PTK bisa menyebar kepada guru-guru sehingga bisa diadaptasi dan memberikan dampak yang signifikan 
terhadap pengajaran di sekolah, bahkan di luar institusi pendidikan guru tersebut mengajar.

Menurut Afandi (2014) guru merupakan orang yang paling tahu permasalahan dalam kelas sehingga dialah yang paling tahu tentang apa yang harus diperbaiki. Selain meningkatkan hasil pembelajaran, PTK juga bermanfaat bagi peningkatan karir guru. Zahro (2019) menuliskan berdasarkan keputusan Menteri Negara Pendayagunaan Aparatur Negara nomor 84/1993 tentang Jabatan Fungsional Guru dan Angka Kreditnya, PTK bisa menjadi jalan untuk meningkatkan kepangkatan guru karena memiliki angka kredit. Kenaikan kepangkatan guru merupakan pengakuan profesi yang berimbas pada peningkatan kesejahteraan.

Akan tetapi apabila kita melihat pada kenyataan yang ada, tidak semua guru memahami apa sebenarnya PTK itu sendiri. Fitria, Kristiawan, \& Rahmat (2019) menyimpulkan dalam penelitiannya bahwa pada dasarnya seorang guru yang telah memahami dan menemukan permasalahan-permasalahan yang didapat di kelas, telah melakukan penelitian tindakan kelas, akan tetapi pelaksanaan dan hasil penelitian tersebut belum dituangkan dalam bentuk format penulisan yang sesuai dengan Penelitian Tindakan Kelas (PTK). Begitupun dengan hasilnya, belum dilaporkan dan dipublikasikan sesuai dengan kaidah pedoman yang ditetapkan. Penelitian Pramswari (2016) juga menemukan bahwa banyak dari para guru yang sangat minim informasi tentang Penelitian Tindakan Kelas (PTK). Kebanyakan dari mereka memperoleh pengetahuan tentang PTK adalah saat menempuh studi S1 atau dari Kelompok Kerja Guru (KKG) yang diikuti.

Permasalahan di atas juga ditemukan ketika penulis berkomunikasi dengan ketua Musyawarah Guru Mata Pelajaran (MGMP) Bahasa Inggris SMA Kabupaten Barito Kuala, Kalimantan Selatan. Banyak dari anggota MGMP yang masih tidak percaya diri untuk memulai PTK karena dua sebab utama, yaitu terbatasnya pengetahuan tentang PTK itu sendiri dan masih belum begitu yakin tentang kelayakan hasil penelitian mereka bisa diterima di jurnal nasional. Berdasarkan hasil diskusi bersama maka dosen prodi pendidikan Bahasa Inggris Universitas Muhammadiyah Banjarmasin berinisiatif untuk melaksanakan Pengabdian Masyarakat (PKM) kepada para guru MGMP Bahasa Inggris. PKM berbentuk pelatihan yang dilaksanakan selama satu hari dan ditindaklanjuti melalui bimbingan hingga artikel penelitian berhasil diterbitkan.

\section{PERMASALAHAN}

Mitra dalam PKM ini adalah MGMP Bahasa Inggris SMA Kabupaten Barito Kuala, Kalimantan Selatan. Berdasarkan diskusi terkait kebutuhan peningkatan pengetahuan dan keterampilan guru, mereka mengemukakan beberapa masalah sebagai berikut:

1. Pengetahuan tentang penelitian tindakan kelas masih perlu ditingkatkan karena beberapa guru masih bingung untuk memulai penelitian mereka.

2. Beberapa guru masih belum percaya diri untuk menerbitkan penelitian mereka di jurnal nasional. 
3. Guru masih belum banyak mengetahui tentang bagaimana mengakses jurnaljurnal bereputasi sebagai referensi penelitian mereka.

Berdasarkan permasalahan tersebut maka ditawarkan solusi untuk mengadakan pelatihan yang membahas tuntas tentang cara membuat desain penelitian tindakan kelas. Pelatihan ini bertujuan untuk membantu guru mempelajari tahapan-tahapan dalam penelitian tindakan kelas, menganalisis contoh artikel PTK yang sudah terbit di jurnal nasional, dan memberikan informasi terkait cara mengakses jurnal bereputasi untuk meningkatkan kualitas sumber referensi penelitian tindakan kelas yang akan mereka laksanakan.

\section{METODE PELAKSANAAN}

PKM dilaksanakan dalam bentuk pelatihan berkelanjutan. Pelatihan bertempat di Universitas Muhammadiyah Banjarmasin selama satu hari penuh. Peserta pelatihan adalah guru-guru pengajar bahasa Inggris yang tergabung dalam MGMP Bahasa Inggris SMA Kabupaten Barito Kuala, Kalimantan Selatan. Peserta berjumlah 20 orang. Di akhir kegiatan, beberapa peserta diwawancara untuk mendapatkan umpan balik atas kegiatan PKM yang telah dilaksanakan. Pelatihan dilanjutkan melalui bimbingan personal setelah para guru tersebut memulai penelitian tindakan kelas mereka. Mereka bisa kapan pun berkonsultasi dengan para pemateri hingga artikel PTK mereka siap diterbitkan.

\section{PELAKSANAAN}

Acara dimulai dengan penandatanganan Memorandum of Understanding (MoU) antara kedua belah pihak, yaitu Prodi Pendidikan Bahasa Inggris UM Banjarmasin dan MGMP Bahasa Inggris Kabupaten Barito Kuala. Salah satu isi MoU tersebut adalah memfasilitasi pelatihan yang diperlukan para guru, termasuk bimbingan penulisan artikel dan penelitian bersama. Pelatihan dibagi ke dalam beberapa tiga sesi sesuai materi yang diberikan, yaitu 1) penelitian tindakan kelas, 2) analisis artikel PTK, 3) akses jurnal bereputasi sebagai sumber referensi.

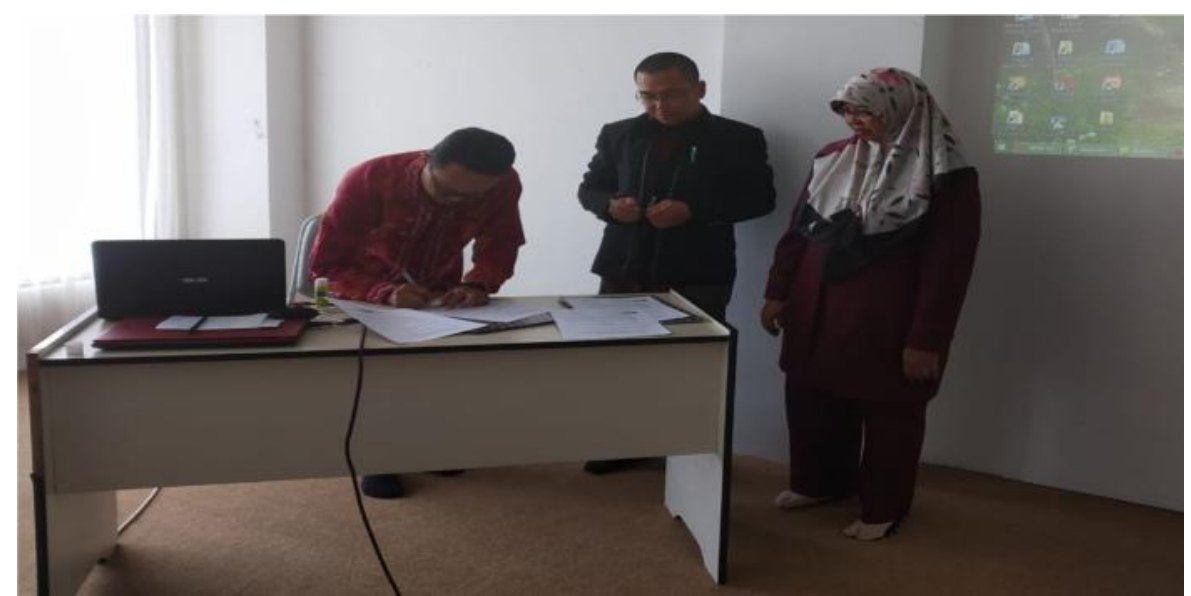

Gambar 1. MoU antara Prodi Pendidikan Bahasa Inggris dan MGMP Bahasa Inggris Kabupaten Barito Kuala 
Pada materi tahapan penelitian tindakan kelas, pemateri memberikan uraian lengkap mengenai apa itu PTK, bagaimana menemukan masalah dalam PTK, membuat instrumen PTK, dan analisis data PTK. Pada sesi ini, materi disampaikan melalui metode ceramah yang kemudian diikuti oleh diskusi. Pada bagian diskusi, guru diminta untuk mengemukan masalah yang mereka temui dalam kelas, memilih strategi pengajaran yang tepat untuk mengatasi salah satu masalah tersebut. Berdasarkan masalah dan solusi yang dikemukan, secara berkelompok guru membuat rancangan sederhana PTK yang akan mereka laksanakan. Mereka menyusun rumusan masalah, tahapan, instrumen pengumpulan data dan analisis data. Kegiatan ini membuka wawasan mereka bahwa sebenarnya masalah dalam PTK selalu ada dalam kelas. Selaras dengan yang dikemukan Latief (Latief, 2012) bahwa tujuan PTK adalah menemukan strategi pengajaran yang tepat untuk mengatasi masalah yang ditemukan guru di dalam kelas. Setelah kegiatan ini, mereka sepakat bahwa PTK sangat bermanfaat untuk meningkatkan keterampilan mengajar sekaligus kualitas belajar siswa di dalam kelas.

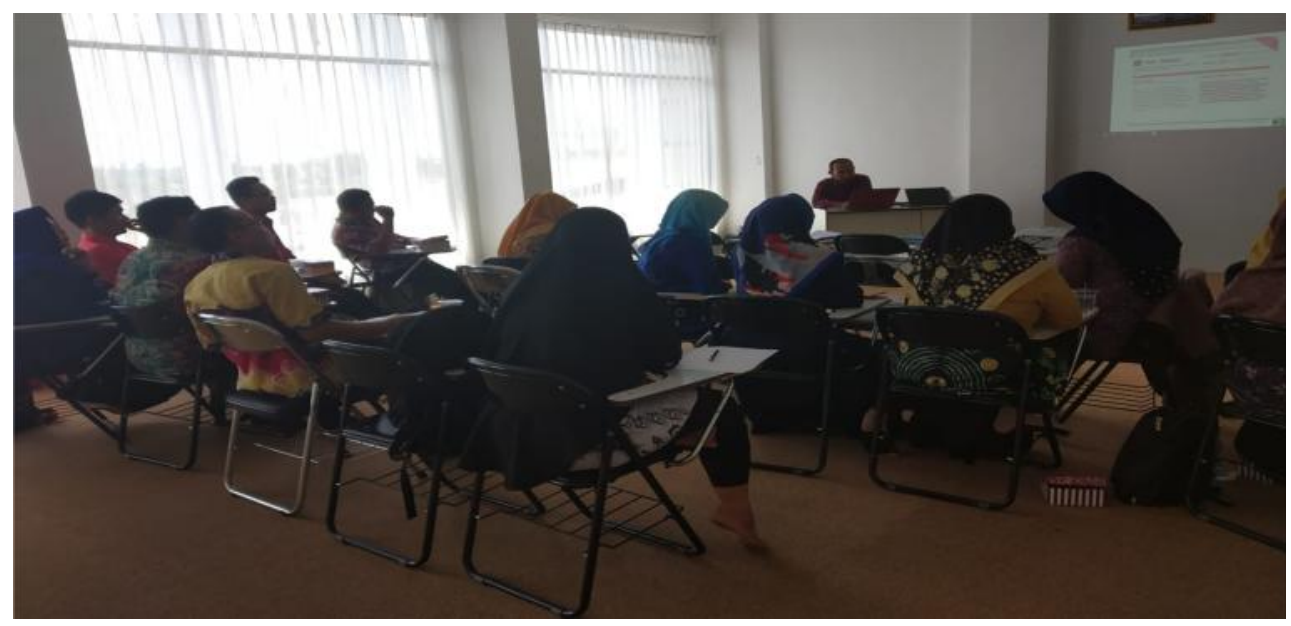

Gambar 2. Peserta mendengarkan penjelasan dari Pemateri

Materi berikutnya adalah analisis artikel PTK. Kegiatan ini bertujuan untuk memberikan pengetahuan bagi guru tentang teknik penulisan hasil penelitian untuk diterbitkan di jurnal nasional. Hal ini sangat berguna mengingat artikel yang dimuat dalam jurnal nasional menjadi salah satu prasayarat kenaikan pangkat mereka. Selain itu, melalui jurnal nasional guru bisa membagikan hasil penelitian tindakan mereka secara luas sehingga memberikan dampak yang lebih besar bagi kemajuan pendidikan di Indonesia. Pada kegiatan ini, pemateri berfungsi sebagai fasilitator karena para peserta bertugas untuk menganalisis artikel secara berkelompok. Setiap kelompok terdiri dari empat sampai lima orang dan satu kelompok menganalisis satu artikel PTK. Mereka diminta untuk membutiri apa saja yang harus ada dalam abstrak, pendahuluan, metode, hasil dan pembahasan, serta kesimpulan. Pada kegiatan ini para peserta terlihat aktif saling berdiskusi dan mengemukan apa yang mereka temukan. Menurut beberapa peserta kegiatan ini sangat bermanfaat karena mereka bisa langsung membedah artikel 
PTK sehingga bisa menjadi modal untuk menulis artikel mereka nantinya. Beberapa mengemukakan bahwa selama ini tidak percaya diri untuk mempublikasi artikel ke jurnal nasional karena tidak tahu bagaimana cara memulai dan takut ditolak oleh pengelola jurnal karena kualitas tulisan mereka. Setelah mengikuti pelatihan, peserta merencanakan untuk menulis artikel mereka dan akan berkonsultasi kepada pemateri sebelum diserahkan ke jurnal. Kolaborasi ini membangkitkan motivasi untuk menulis dan membagi hasil penelitian mereka.

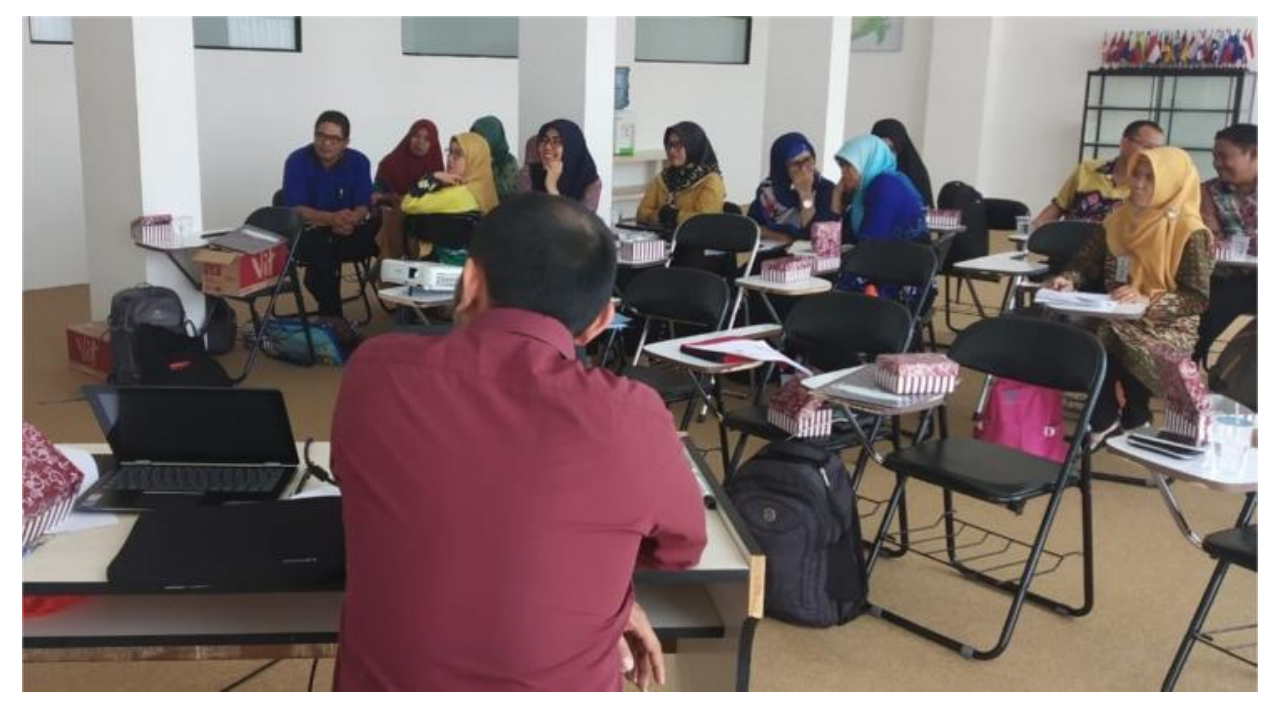

\section{Gambar 3. Peserta dikelompokkan untuk mendiskusikan Rancangan Penelitian mereka}

Materi terakhir adalah akses jurnal sebagai sumber referensi. Materi disampaikan melalui metode ceramah disertai praktik dengan menunjukkan berbagai website yang bisa dikunjungi. Peserta diajarkan untuk mencari sumber referensi berdasarkan kata kunci dalam penelitian mereka dalam website, seperti Google Scholar. Selain itu, mereka juga diarahkan untuk memiliki akun sosial media peneliti, misal researchgate.net atau academia.edu. Pencarian website jurnal berakreditasi juga ditunjukkan dengan mengunjungi website pengindeks jurnal seperti Sinta. Selain itu, peserta juga ditawarkan untuk berkolaborasi dengan peneliti di prodi pendidikan Bahasa Inggris karena mereka memiliki akses jurnal yang lebih luas. Kegiatan ini sangat membantu para guru yang sebelumnya hanya mengandalkan buku sebagai bahan referensi atau Google sebagai alat pencari.

\section{HASIL DAN LUARAN}

Berdasarkan uraian pelaksanaan di atas maka dapat dikemukan hasil dari PKM yang telah dilaksanakan sebagai berikut:

1. Peserta memahami tahapan penelitian PTK. Berdasarkan hasil observasi, $80 \%$ dari peserta mampu merumuskan masalah dan membuat rancangan penelitian mereka secara berkelompok. 
2. Peserta menjadi lebih percaya diri untuk menulis artikel PTK. Mereka telah memahami teknik menyusun artikel berdasarkan analisis terhadap contoh yang diberikan.

3. Peserta memiliki tambahan wawasan terkait cara memperoleh sumber referensi berupa jurnal bereputasi. Berdasarkan hasil evaluasi, mereka telah memahami berbagai alternatif pencarian sumber referensi untuk meningkatkan kualitas tulisan.

Setelah kegiatan ini selesai, luaran yang diharapkan adalah kolaborasi penelitian antarpeserta atau peserta dengan dosen pendidikan bahasa Inggris Universitas Muhammadiyah Banjarmasin. Kolaborasi ini bisa meningkatkan kualitas publikasi sekaligus kualitas pembelajaran bahasa Inggris SMA di Kabupaten Barito Kuala, Kalimantan Selatan.

\section{KESIMPULAN}

Kegiatan PKM ini memberikan manfaat dalam meningkatkan pengetahuan dan keterampilan guru dalam melaksanakan penelitian tindakan kelas. Penelitian tindakan kelas merupakan salah satu cara untuk meningkatkan kualitas pembelajaran sekaligus profesionalisme guru. Berdasarkan hasil wawancara dan observasi disimpulkan bahwa sebagian besar peserta telah memahami tahapan dalam penelitian tindakan kelas serta telah mampu membuat rancangan penelitian. Mereka juga menjadi lebih percaya diri untuk menulis hasil penelitian dan mempublikasikannya dalam jurnal nasional. Pelatihan ini membuka wawasan mereka terkait cara mengakses jurnal bereputasi untuk meningkatkan kualitas sumber referensi. Setelah kegiatan ini, diharapkan para peserta bisa saling berkolaborasi untuk mengerjakan dan mempublikasikan hasil penelitian mereka. Peserta juga diberikan kesempatan untuk terus berkomunikasi dengan pemateri PKM jika selama pelaksanaan penelitian terdapat kendala.

Saran bagi peserta adalah untuk terus menjalin komunikasi dan melakukan peer review terhadap penelitian yang mereka laksanakan. MGMP diharapkan bisa memfasilitasi peserta agar memiliki pertemuan rutin yang membahas kemajuan penelitian. Sekolah juga seharusnya bisa memberikan dukungan pada guru agar terus meningkatkan publikasi.

\section{DAFTAR PUSTAKA}

Afandi, M. (2014). Pentingnya Penelitian Tindakan Kelas Bagi Guru Dalam Pembelajaran di Sekolah Dasar. Jurnal Ilmiah, 1(1), 1-19. https://doi.org/10.1007/s13398-014-0173-7.2

Fitria, H., Kristiawan, M., \& Rahmat, N. (2019). Upaya Meningkatkan Kompetensi Guru Melalui Pelatihan Penelitian Tindakan Kelas. Abdimas Unwahas, 4(1), 1425. https://doi.org/10.31942/abd.v4i1.2690

Latief, M. A. (2012). Research Methods on Language Learning: An Introduction (First Edit). Malang: UM Press. 
Volume 4, Nomor 1, Maret 2020

Pramswari, L. P. (2016). Persepsi Guru SD terhadap Penelitian Tindakan Kelas. Mimbar Sekolah Dasar, 3(1), 53-68. https://doi.org/http://dx.doi.org/10.17509/mimbar-sd.v3i1.2356

Zahro, N. H. (2019). PKM Pelatihan Penulisan Karya Tulis Ilmiah Bagi Guru Sekolah Dasar Kecamatan Situbondo di SD Islam Al Abror. Dedication: Jurnal Pengabdian Masyarakat, $\quad 3(2), \quad 89-98$. https://doi.org/https://doi.org/10.31537/dedication.v3i2.236 
Volume 4, Nomor 1, Maret 2020 